\title{
De series televisivas, intensidades y miedos posmodernos ${ }^{1}$
}

\section{Of television series, intensities and postmodern fears}

Ariel Gómez Ponce ${ }^{2}$

\section{Resumen}

Atenta al modo en que los afectos colonizan las formas culturales, la teoría narrativa desarrollada por Fredric Jameson contiene claves de interés para interrogarnos cómo el miedo, en tiempos recientes, emerge como una intensidad: una conmoción subjetiva que trasciende la posibilidad de ser comunicada, pero que deja huellas en las materialidades artísticas. Me ocuparé de relevar el alcance de esta categoría, a la luz de un conjunto de series televisivas que hacen del miedo y sus estados críticos un lugar de enunciación. La perspectiva de Jameson permitirá alcanzar cierto grado de generalización mediante el reconocimiento de procedimientos de representación, tales como las experiencias episódicas de los personajes, la preponderancia por los espacios de lo íntimo y los efectos de extrañamiento que atraviesan algunas matrices genéricas dominantes. El objetivo de este trabajo radica en iniciar una regularización coherente de series actuales que escenifican los desbordes del miedo en el cuerpo social, al tiempo que

\begin{abstract}
Attentive to the way that the affects colonize the cultural forms, the narrative theory developed by Fredric Jameson contains keys of interest to question how fear, in recent times, emerges as an intensity: a subjective commotion that transcends the possibility of being communicated, but which leaves traces in the artistic materialities. The aim of this work is to reveal to the scope of this category, in light of a set of TV series that make fear and its critical states a place of enunciation. The perspective of Jameson allows certain degree of generalization through the acknowledgement of procedures of representation, such as the episodic experiences of the characters, the preponderance of the intimate spaces, and the effects of strangeness that pierce through some dominant generic matrixes. The objective is to start a coherent regularization of current series that dramatize the overflow of fear in the social body, and, at the same time, signal systemic changes introduced by the cultural experience of postmodernity.
\end{abstract}

${ }^{1}$ Trabajo recibido el 27/07/2019. Aceptado el 17/10/2019.

${ }^{2}$ Universidad Nacional de Córdoba. Consejo Nacional de Investigaciones Científicas y Técnicas. Contacto: arielgomezponce@unc.edu.ar 
señalan cambios sistémicos introducidos por la experiencia cultural de la posmodernidad.
Keywords: Fear; Intensities; TV series; Fredric Jameson; Posmodernity

Palabras clave: Miedo; Intensidades; Series televisivas; Fredric Jameson; Posmodernidad

Poco tiempo después del 11 de septiembre de 2001, el filósofo Fredric Jameson (2002) expresó abiertamente sus resguardos ante el patriotismo exacerbado, pero también hacia esa histeria colectiva que los ataques introdujeron, afectando por igual tanto a las víctimas de los atentados, como a quienes no perdieron a nadie e, incluso, se hallaban en otras latitudes. Porque el 11-S, un acontecimiento localizado, repercutió homogéneamente a escala global, despertando un caudal de reacciones idénticas que, de manera rauda, se identificaron y universalizaron bajo la rúbrica del miedo.

Por aquellos años, Jameson sugirió repensar esa aparición «natural y evidente» del miedo al amparo del esfuerzo mediático por presentarlo como un efecto unánime en el cuerpo social. Aquella paranoia global, enmarcada en ese poliédrico fenómeno que reconocemos como Cultura del Miedo, debía atenderse, entonces, a la luz de medios masivos que, insistentemente, repitieron retratos colectivos del terror hasta casi agotar su campo semántico. Incluso, el filósofo nos advirtió, entonces, de la necesidad imperante de incrementar toda crítica dialéctica sobre ese atentado «con esta otra dimensión estética y orientada hacia la sociedad de la imagen», en tanto la materialidad artística supuso uno de los primeros intentos por colonizar la tragedia $(2002$, p. 7$)$.

De modo que la pregunta acerca de la veracidad afectiva del miedo durante el 11-S conlleva, para Jameson, interrogantes de mayor complejidad: ‘cómo develar esa paranoia que parece responder más a la interposición de un estereotipo que a una respuesta espontánea? ¿Cómo captar la mecánica de un delirio colectivo, librándolo «de su orquestación y de su amplificación mediática» $(2002$, p. 3)? ¿De qué manera, finalmente, los materiales culturales fueron y son capaces de modelizar los efectos del miedo sobre el cuerpo social?

Por su actualidad y repercusión internacional, creo que las series televisivas actuales contienen las pistas decisivas para comprender cómo, a casi veinte años del $11-S$, la cultura resuelve las contradicciones históricas del miedo. Incluso, si la afirmación de Dominique Moïsi (2017) re- 
sulta cierta y estas ficciones están conformando «un catálogo ilustrado, un compendio de los miedos del mundo» (p. 188), ellas devienen un espacio privilegiado para interrogarnos cómo las expresiones que atañen a la paranoia colectiva recomponen nuevos avatares sociopolíticos, que son traducidos a las micropolíticas de sus narrativas, pero que responden siempre a los modelos que Estados Unidos impone mediante su prisma ideológico.

Percibo, no obstante, que un número importante de series insiste en escenificar los desbordes del miedo, estados críticos de este afecto que lindan con las irrupciones de la desmesura. Hablo de relatos que aluden a las secuelas que el miedo deja en el cuerpo social, componiendo una atmósfera tensa donde proliferan la paranoia, la inseguridad y la amenaza constante, enclave en torno al cual las narrativas no arriesgan definiciones. Hay, por ende, el acecho de algo indecible en las apariciones más recientes del miedo, que trasciende la posibilidad de ser comunicado, pero que la forma audiovisual se esmera por señalar y recomponer.

Entiendo que la apuesta teórica de Fredric Jameson puede colaborar con el desarrollo de herramientas que hagan visible esta fluencia innombrable del miedo. Vale aclarar que el problema del miedo como cuestión social no es central en Jameson, pero su edificio teórico contiene observaciones que interesan destacar por el modo en que el filósofo resuelve el tipo de textura narrativa que desarrolla. Mi recorrido pretende, por lo tanto, relevar solo algunos enclaves de lo que Jameson propone como una teoría narrativa afectiva, atenta ella a la «forma en que el afecto se apropia de todo un aparato narrativo y lo coloniza» (2013, p. 94). Se trata de una reflexión que debe ser comprendida en el marco de su poética de las formas sociales, vasto proyecto intelectual orientado a indagar cómo los artefactos estéticos escenifican contenidos históricos en el contexto de determinadas condiciones socioeconómicas.

Desde esta propuesta, el presente trabajo recuperará su noción de intensidades, en tanto forma de conmoción subjetiva que introduce la experiencia cultural de la posmodernidad, sostenida en las formas artísticas mediante un conjunto de procedimientos de representación que atañen a las experiencias episódicas de los personajes, la preponderancia por los espacios de lo íntimo, y los efectos de extrañamiento de atraviesan algunas matrices genéricas. En tal sentido, propondré un recorrido descriptivo, pertinente para reconocer el modo en que un conjunto de propuestas estéticas hace del miedo y sus derivas un lugar de enuncia- 
ción, ofreciendo cierto grado de generalización que permita iniciar una regularización coherente de estas series televisivas, erizadas de en tensiones históricas y políticas.

\section{Puntos de partida}

El problema del miedo, tal como lo plantea Fredric Jameson, debe interrogarse dentro de ese creciente interés por el estudio de las afectividades y los modos culturales del sentir. En términos más generales, hablo de ese giro afectivo que, en tiempos recientes, ha cobrado especial relevancia en las ciencias sociales y humanas, en lo que aparenta ser una reacción directa a ese otro giro conocido como textual, de cuño postestructural y de vocación discursiva, que habría relegado lo corporal y lo emocional a un plano secundario (Cfr. Arfuch, 2018, pp. 21-22). En cierto modo, y sin permanecer ajeno al debate, la apuesta teórica de Jameson pretende reconciliar la disputa entre estos giros al interrogar afecto y lazo social a la luz del tipo de la forma material que cobra en la posmodernidad.

En tal sentido, su propuesta le otorga un lugar especial a esa materialidad artística que puede documentar el surgimiento de estados «que no han sido nombrados y no están disponibles para la conciencia, o que son absorbidos por las subjetividades en diferentes formas que los tornan inadvertidos e indistinguibles» $(2013$, p. 46). Pues, en Jameson, está siempre la idea de que el arte busca colonizar zonas inexploradas e inexpresadas que responden a intensos cambios históricos, los cuales siempre generan desafíos en cuanto a la representación de las subjetividades y de sus percepciones. Ello trata, en efecto, con una contienda que las narrativas masivas asumieron en su intento por recomponer el 11-S, cuestión que bien puede atenderse en una bifurcación de sumo interés que quisiera describir en más detenimiento.

Sabido es que, desde la Guerra Fría hasta avanzada la década de los noventa, Hollywood retrató las ansiedades sociales a través de las catástrofes más o menos creativas. Basta recordar el modo en que exitosos filmes como Deep Impact (Leder, 1998) o Independence Day (Emmerich, 1996) reelaboraron ese sentimiento nacional de inseguridad ante un mundo polarizado, ora a la forma de un cometa a punto de estrellarse, ora de la invasión extranjera de aliens en busca de recursos. Y si bien, por estas largas tradiciones de la ciencia ficción, lo post-apocalíptico o el 
horror, no podría decirse que el derrumbe del World Trade Center fuera un hecho inimaginable, su impacto vino a quebrar «las coordenadas simbólicas que determinan nuestra experiencia de la realidad», afectando fuertemente a la representatividad de las producciones masivas (Žižek, 2013 , p. 19). Refiero a una hipótesis insistente en numerosos autores quienes acuerdan en afirmar que los atentados inauguran una zona problemática en el orden de lo verosímil, consecuencia de su previa elaboración mediática (Cfr. Augé, 2014; Mondzain, 2016).

De modo especial, dicho punto de inflexión se hallaría en aquella dramatización secuencial del 11-S que, en vivo y en directo, fue montada por informativos que redujeron la incertidumbre del acontecimiento a la lógica de la narración, los criterios de la ficción y a una memoria de la iconografía cinematográfica (Lozano, 2004). Porque el relato épico del «America Under Attack», impuesto globalmente por la $\mathrm{CNN}$, habría supuesto el primer intento por volver inteligible una catástrofe cuyo carácter «espectacular» (su «naturaleza en esencia estética», dirá Jameson, 2002, p. 7) solo podía traducirse a través de esos lenguajes otrora introducidos por Hollywood. La pregunta que emerge, entonces, es qué asidero encontró la industria de contenidos para colonizar la tragedia y reinventar las gastadas ficciones bélicas y apocalípticas que se volvieron tangibles.

Si, como sugiere la hipótesis de Marie-José Mondzain (2016) el 11-S supuso «el golpe más grande al imperio de lo visible» (p. 10), la vacilación de ese cine que se mostró cauto y políticamente correcto (depurándose de toda violencia, muerte y combate) parece dar habida cuenta de ello. Incluso, puede señalarse la inexistencia de filmes dedicados al acontecimiento, exceptuando aquellos dos (United 93 y World Trade Center) que, en el quinto aniversario del evento, relataron más bien sus aspectos periféricos, aunque eludiendo cualquier mensaje político posible (Žižek, 2006).

Pero, ante el silencio del cine, las series televisivas se colocaron en el frente de batalla con sus relatos más flexibles a la hora de retratar el hecho histórico. Ellas asumieron el riesgo de ficcionalizar el 11-S, tanto durante el periodo en cuestión (como es el caso de las exitosas 24, Third Watch o The West Wing) como también en tiempos recientes (y Homeland, en tal sentido, representaría hoy el máximo exponente). Tal vez porque muchas ya se encontraban abocadas al terrorismo y la guerra, o quizá porque podían «ajustar» sus contenidos en cada episodio según el agrado del público sensibilizado, estas «ficciones colaterales» aparecie- 
ron para barajar todo tipo de hipótesis sobre las respuestas políticas y las causas de uno de los golpes más estremecedores hacia los Estados Unidos. $^{3}$

Sin embargo, no me preocuparé aquí por este cúmulo de relatos que optaron por reproducir de modos más o menos explícitos la tragedia, algo que he explorado en trabajos previos (Gómez Ponce, 2018). Quisiera llamar la atención, más bien, acerca de otros recorridos estéticos que aluden a las secuelas que el acontecimiento legó en el cuerpo social o, si se prefiere, de series que hacen del miedo y sus derivas un lugar de enunciación. Narradas en el marco de diferentes variedades genéricas, estas ficciones coinciden en trasladar la incertidumbre, el peligro y la sospecha hacia el centro de sus contenidos temáticos. Ellas componen, incluso, una atmósfera tensa donde proliferan los enemigos aparentemente inocuos, la sensación de inseguridad y la amenaza constante e inminente de una tragedia, enclave en torno al cual las narrativas parecen no arriesgar definiciones. Hay, en tal sentido, algo innombrable en las apariciones más recientes del miedo que, sin embargo, toma forma audiovisual tal vez porque, como supone Patrick Boucheron (2016), «la imagen vuelve visible lo que se oculta bajo el desgaste de las palabras» (p. 30).

Sin extenderme acerca de las dificultades analíticas a la hora de evaluar las huellas discursivas de las configuraciones afectivas (Arán, 2015), entiendo que estas emergencias del miedo instauran un desafío en el análisis de las series y, junto a Jameson, reconozco «que necesitamos un tipo diferente de lenguaje para señalar el afecto sin nombrarlo, presumiendo definir su contenido» (2013, p. 29, cursiva en el original). Y me parece advertir que la clave yace en cómo este conjunto de series coincide en presentar un estado crítico de los afectos sociales que linda con las irrupciones de la desmesura, con cierta dimensión irracional de las pasiones, y con «todo un subsuelo emocional» que el filósofo ha dado en llamar intensidades, esa forma de conmoción subjetiva que introduce la nueva experiencia cultural de la posmodernidad (1996, p. 28).

Vale señalar que, a través de esta noción, Jameson pretende resolver uno de los rasgos constitutivos de la subjetividad posmoderna: una nueva superficialidad emocional que gana visibilidad en el capitalismo

\footnotetext{
${ }^{3}$ Remito, especialmente, a la minuciosa investigación realizada por de Felipe e Gómez (2011), quienes han elaborado un catálogo de las series y el modo en que problematizaron el 11-S. Una lectura similar es desarrollada por Pérez Pereiro (2012).
} 
tardío y en esa sociedad del «simulacro» que hace de lo pasajero y lo efímero su regla (Baudrillard, 1993). Como fenómeno de la posmodernidad, la propuesta jamesoniana asume que las intensidades responden a la disolución del sujeto centrado y de sus viejos afectos modernistas, en lo que da lugar a «la creciente fragilidad y vulnerabilidad del antiguo individualismo burgués, a su deterioro bajo las condiciones de instituciones a gran escala» (2012, pp. 40-41).

Pero se trata, no obstante, de una categoría sobre la cual el filósofo no ahonda en mayores definiciones, aunque intuyo que puede comprenderse más acabadamente a la luz de ciertas narrativas sintomáticas que dan cuenta de un cambio cultural sistémico más profundo y del modo en que este se escenifica a través de ciertos procedimientos de representación. Es a partir de este estímulo inicial que propongo un sucinto recorrido por algunas series recientes, actualizando reflexiones jamesonianas pertinentes para hacer visible esta fluencia del miedo y la manera en que se intensifica y toma forma artística en la cultura masiva actual.

\section{Intensidades y series de TV}

The Leftovers (HBO, 2014-2017), una de las series más exitosas de los últimos años (aunque, también, una de las más desoladoras), centra su relato en las consecuencias de un misterioso evento global, en el cual el $2 \%$ de la población desaparece imprevisiblemente. A tres años del incidente, recompone un coral de testimonios de un poblado de New York que, agobiado por el dolor, se interroga insistentemente cómo vivir con la ausencia del otro, partida repentina («sooner departure», dirán) que no encuentra explicación. Y aunque juega con el espectador ofreciéndole incontables hipótesis que sugieren sin afirmar nada, la ficción focaliza en retratar el modo en que la tragedia cala profundo en las subjetividades y en una memoria colectiva que se tensa entre el temor a olvidar a quienes ya no están, pero también en el tormento de recordarlos.

Interesa, empero, la forma en que The Leftovers habita esa cotidianeidad con un sentir innominado, cierto estado de conmoción que los personajes no pueden o no saben describir. Porque, sin resolver jamás el enigma de la desaparición masiva, la serie avanza en el relato individual de sus protagonistas, deteniéndose de a ratos en su angustia, en una histeria que no puede verbalizarse, pero que se expresa en pequeños 
raptos de desesperación, de comportamientos erráticos y de llantos en solitario que parecen reflejar un incesante pavor colectivo de cara a otra posible evaporación global.

Creo que Jameson (1996) coincidiría en sugerir que este relato ilustra claramente su idea de intensidades, en tanto la ficción muestra esos cambios bruscos de la experiencia afectiva que «tienden a estar dominados por una peculiar euforia» (p. 36). Ello refiere a una clase particular de afectos, de carácter mutable e inestable, que no encuentran parámetros inequívocos para su descripción pues adquieren sentido solo cuando se los «registra según su volumen» $(2013$, p. 47). Pienso, especialmente, en la desgarradora historia de Nora Durst, protagonista de la serie cuya familia entera se ha desvanecido. A lo largo de las tres temporadas, el vaivén emocional de Nora oscilará, sin estadios intermedios, entre en el optimismo por seguir adelante y un inmenso pánico que fluctúa entre no poder hallarle un nuevo sentido a su vida o bien hacerlo y que sus tres hijos y su marido retornen.

De allí que Jameson reconozca que intensidades de este tipo producen, más bien, un cromatismo delimitado por pares opuestos y dicho deslizamiento puede observarse, por ejemplo, en las transiciones de la melancolía a la euforia o del depresivo al maníaco, donde cada momento se diferencia del anterior por un aumento o una disminución en el grado de intensificación. En tal sentido, su propuesta desliza un primer acercamiento metódico para el estudio de los afectos: al señalar cierto carácter más cuantitativo que cualitativo, las intensidades deben evaluarse al amparo de esa «escala deslizante» constituida por antinomias, puesto que esta modalidad afectiva «no estaría más exenta que ninguna otra cosa del juego semiótico de las oposiciones» (2013, p. 89). Jameson destaca, sin embargo, que mientras un extremo de las intensidades supone una constante cultural, será su opuesto aquel que varíe, dependiendo de la impronta que el texto le otorgue y de la manera en que la figura heroica (ese «aparato registrador», dirá en un sentido cara a Bakhtin) lo exprese en sus experiencias episódicas.

Esta idea de cromatismo parece replicarse en Here and Now (HBO, 2018) cuyo protagonista perseguido por la simbología del número 1111, será apoderado por una fuerte premonición: un peligro incierto, pero inminente, se acerca a su comunidad. Las visiones de Ramón son, no obstante, consideradas por su entorno como un delirio que se presume hereditario y el elemento sobrenatural es intervenido, insistentemente, por los avatares de esta familia multirracial y progresista, inmersa en los 
Estados Unidos más conservadores. Pero, a la utopía de una vida apacible en los suburbios y de ese clan idílico, se contraponen los lapsos de paranoia de un personaje frágil, agobiado por las crisis existenciales y perseguido por fantasmas que intentan advertirle sobre un secreto familiar que el relato (como en The Leftovers) no resolverá jamás.

$\mathrm{O}$ valga de ejemplo, también, el modo en que el reciente desenlace de la exitosa Game of Thrones (HBO, 2011-2019) confeccionó otro cromatismo, no sin despertar controversias. Daenerys, una de sus personajes más emblemáticas y que deleitara al público con su vocación revolucionaria, cierra su arco narrativo con un imprevisible arrebato de locura. Aquella Madre de Dragones, que durante ocho temporadas insinuó la posibilidad de un poder femenino en el trono, asesina a miles luego de afirmar que «si no es por amor, que sea por miedo». Interesa que, desde sus comienzos, la serie habría estado expresando esta antinomia donde la intensidad del sujeto femenino empoderado solo puede oscilar entre el amor (principalmente, maternal) y el miedo colérico, quizá porque, como afirma Slavoj Žižek, «ver a Daenerys loca de furia volando en un dragón y quemando casas y personas, expresa la ideología patriarcal con el miedo hacia las mujeres fuertes en política» (2019). Se trata de una lógica que se replica en otros personajes (Cersei, Olenna), pero también en otras ficciones que priorizan lo femenino como un lugar de debate (pienso, por ejemplo, en House of Cards y la gélida Claire Underwood cuyos únicos momentos de explosión expresan ora la desesperación por no poder legar descendencia, ora el pánico que despierta en todo potencial enemigo).

Con todo, las intensidades desplegadas por The Leftovers y Here and Now introducen, en cierto modo, los traumas del 11-S, aunque bien como una causa ausente. Una vacancia similar puede percibirse en la miniserie Chernobyl (HBO, 2019), cuya historia, más que la dramatización del desastre nuclear, prioriza el desconcierto de una comunidad que no acaba de comprender lo sucedido. La ficción opta, entonces, por disminuir el acontecimiento (por lo demás, de público conocimiento) en vistas de cartografiar una atmósfera sombría, habitada por cuerpos radiactivos y en deterioro, y por una población que, en constante estado de alerta, sospecha la tragedia y los ocultamientos del gobierno soviético. «El verdadero peligro -afirmará uno de los protagonistas- es que, si escuchamos suficientes mentiras, entonces ya no reconocemos la verdad». 


\section{Variaciones genéricas y orden de lo íntimo}

Se objetará con razón que estas series aludidas evitan toda mención del miedo; que los personajes que en ellas habitan esquivan su verbalización, como si el temor que disloca los cuerpos y las subjetividades excediese las capacidades del lenguaje. Pero, en estas ficciones, el miedo se nos hace visible en cierto carácter espectral, en el acecho de algo indecible que trasciende la posibilidad de ser comunicado, pero que las intensidades de sus personajes pretenden señalar y que la forma audiovisual se esmera por recomponer.

Jameson dirá que esto se puede explicar como un intento por representar lo terrible y lo informe, y que, en tanto persigue una participación sentimental por parte del espectador, la experimentación de estas intensidades «se comprende mejor regresando a las antiguas teorías de lo sublime» (1996, p. 28). Pues, entre esa «visión espasmódica» que linda con lo tenebroso (Burke), y la exageración y el grado de artificio del camp (Sontag), el filósofo observa que el efecto de la intensidad sintetiza «algo así como una sublimidad camp o histérica» (1996, p. 53). Y, en torno a este enclave, dirá que

el miedo -la repetición estética del miedo, su expresión artística, su transformación, el disfrute del shock y la conmoción que el miedo le propina al organismo humano- es la aprehensión, por medio de un objeto estético dado, de lo que en su magnitud asombrosa encoge, amenaza, disminuye y censura la vida humana (...) lo sublime toma su objeto como pretexto y ocasión para intuir a través de él una fuerza bruta no figurable, un poder puro, aquello que pasma la imaginación en el sentido más literal (Jamenson, 2014, pp. 460-461)

De ningún modo sería pertinente desviarnos hacia esta discusión, pero esta idea de «lo sublime posmoderno» puede iluminar la heterogeneidad de las series mencionadas, las cuales no recurren a las formas del horror (para Jameson, un género que -como el porno- se reduce a la alternancia entre el shock y su ausencia, 2007[1992], p. 154), sino que nos acercan los efectos del miedo mediante el drama (The Leftovers), la soap-opera (Here and Now), el thriller político (House of Cards) o bien el fantasy (Game of Thrones).

Independientemente del género en que se inscriban, un gesto común atraviesa a todas estas ficciones: el que hace que el miedo se vuelva una instancia menos reconocible, un umbral asediado por esa «fuerza 
bruta» de lo desconocido que se teje entre las fisuras de lo real. En tal sentido, estas series que, pese a sus marcadas diferencias, contienen inflexiones de lo siniestro y la truculencia del gótico, lindan también con otras variantes estilísticas que atañen tanto a lo sobrenatural e inverosímil del fantástico, como al misterio y el estremecimiento que mantiene el policial de suspenso. Esto autoriza a pensar que estas formas en mutación incesante resumen cierta poética de lo irracional, o más bien lo que Pampa Arán (2019) define como un insólito ficcional: «un modo de genericidad que apunta a un efecto de lectura y que se alberga en diferentes géneros», y del cual el sublime gótico ha sido una de sus matrices de emergencia histórica.

Entiendo que, de alguna manera, Jameson sugiere esta idea cuando traza un inventario por esos textos del cine estadounidense que define como conspiratorios o de la paranoia global: conjunto de ficciones que, a fuerza de repetición masiva y reificación mercantil, comenzarán a ser reconocidas como géneros por derecho propio (el cyber punk, la paranoia high-tech, el thriller conspirativo), aunque en ellas yazcan patrones convencionales de otros más «primitivos» (como la novela de espionaje). En todos los casos, se trata de narrativas que revitalizan la temática del complot en términos de una red infinita de confabulaciones sobre la cual, empero, se ofrece «una explicación plausible de su invisibilidad» (2018[1991], p. 39). En estas derivas de la intriga, hay algo perturbador que adquiere un tono extraño puesto que se muestra, como nos diría Piglia, un «sujeto [que] es instrumento de fuerzas que no comprende», pero que se esmera por resolver (2001, p. 5).

Pero, si esta búsqueda de respuestas es, como piensa Jameson, constitutiva de una materialidad artística que siempre interpela sus condiciones históricas, los géneros conspiratorios no harían más que ofrecer «una solución fantástica a los malestares que se apresuran en llenar nuestro vacío actual» (2018[1991], p. 32). De allí que el filósofo interrogue esta eclosión del complot en los cambios sistémicos que acompañan al capitalismo tardío, allí donde el estrepitoso avance tecnológico por los modos de producción nucleares y electrónicos provocó un desplazamiento de interés: la naturaleza, ese otro absoluto que caracterizara a lo sublime tradicional, se ve reemplazada por el miedo hacia el poder maquínico y por la paranoia colectiva ante las técnicas de control y manipulación de la información (entramado que la Guerra Fría, con su efervescencia de métodos para el espionaje y su carrera armamentista de destrucción masiva, legó para la posteridad). 
Es este el sentido de miedo que recupera Westworld (2017), reciente éxito de $\mathrm{HBO}$ que nos ubica en un futuro no muy lejano, cuando la tecnología ha permitido el desarrollo de sofisticados robots y de un campo de simulación donde los humanos pagan por interactuar con ellos. El parque temático (ambientado al estilo Lejano Oeste, en lo que hace a una interesante hibridación entre western y ciencia ficción) devendrá un entorno hostil cuando estos androides adquieran, imprevisiblemente, inteligencia y se subleven contra sus creadores. Lo cierto es que sobre el viejo motivo de la rebelión maquínica se traza, empero, otra línea de significados. Pues aquello que se introduce como un centro de divertimento (un espacio de liberación donde los humanos pueden explorar lo que en el mundo real está vedado) contiene una trama oculta: un complejo sistema que, a través de la interacción con los robots, acopia datos para vender a grandes corporaciones.

Esta narración refleja, a todas luces, la postura de Jameson acerca de que «la tecnología de la sociedad contemporánea es hipnótica y fascinante, no tanto en sí misma como porque parece ofrece un esquema de representación privilegiado para comprender la red de poder y control» (1996, p. 57). Y numerosas series actuales exhiben mecánicas similares en torno a una tecnología sublimada que reprime y corrige a sus sujetosotro, garantizando así la delimitación de roles sociales, como bien sucede en las exitosas Orphan Black (Netflix, 2013), Mr. Robot (USA Network, 2015) o, quizá la más paradigmática, Black Mirror (Netflix, 2011). También, la reciente Homecoming (Amazon Prime, 2018), serie protagonizada por Julia Roberts, reelabora esta apropiación al centrarse en una institución para la reinserción civil de exsoldados que oculta un misterio brutal: un experimento gubernamental para, casualmente, eliminar el miedo y borrar todo trauma, en vistas de reutilizar a los combatientes en nuevos encuentros bélicos.

Con todo, la hipótesis de Jameson apunta a mostrar que, si bien el complot conspiratorio es una narración que pretende resolver sus propios dilemas epocales, se halla inscripta, empero, en esa larga tradición de transformaciones seculares de ese insólito ficcional que señala una ausencia: una «quietud expectante que revela un mundo-objeto suspendido para siempre al borde de la significación, dispuesto para siempre a recibir una revelación» (1989, p. 108). En tal sentido, un hilo conductor muy fuerte en la heterogeneidad de tramas que he señalado yace en una suerte de extrañamiento, de desfamiliarización a través de la cual los estereotipos reconocibles por los personajes en sus vidas cotidianas co- 
mienzan a desmantelarse y reestructurarse, y las atmósferas se perciben como «portadoras» de cierto complot. Lo sublime jamesoniano recupera, bajo estas condiciones, su sentido de una fuerza no figurable que, en las series televisivas, se lograría a través de múltiples procedimientos de representación ceñidos al suspenso, ese «engranaje» que dosifica la información y crea el efecto psicológico del miedo (Cfr. Arán, 2019).

Y me parece advertir que, por esta propensión, las ficciones seriadas insisten en contextualizar el miedo en los espacios domésticos, evocando el devenir familiar como núcleo de sus historias. Basta recordar The Leftovers y Here and Now cuyas tramas, aunque no podría decirse que conspiratorias, ocultan un enigma que debe ser develado, pues la armonía del hogar y de la comunidad suburbial corre riesgo. La misteriosa evaporación masiva en la primera, como el peligro sobrenatural que asoma en la segunda, no importan tanto como esa domesticidad que se ha visto perturbada y de allí el intento desesperado de sus protagonistas por aferrarse a un entorno familiar erosionado por la tragedia. Diría, entonces, que el extrañamiento contenido en estas narraciones no proviene tanto de la crispación social o de las experiencias episódicas de sus personajes, como de una crisis en cuanto a los lugares de lo íntimo donde todo ello transcurre.

Creo que Jameson coincidiría en sugerir que las claves de esta insistencia hay que buscarlas en las transformaciones de la vida social norteamericana durante el contexto de posguerra y en el modo en que Estados Unidos ha definido el modelo de familia nuclear como una sus grandes utopías. Pues otro supuesto recurrente en Jameson (2008) es que «la década de 1950 sigue siendo el más privilegiado de los objetos de deseo perdidos» (p. 56), en tanto periodo de bonanza que cristalizara el acomodaticio imaginario de un American Way of Life y de esa vida en los suburbios que acompañó la expansión de una sociedad de consumo. No obstante, el corolario de la Guerra Fría será el despertar nuevos miedos en la cultura estadounidense, consecuencia de la pérdida de legitimidad gubernamental durante los 70's (el escándalo Watergate, las repercusiones por Vietnam) y de un golpe rotundo al modelo expansivo del Sueño Americano: ello es, una intensa desestabilidad económica, promovida por la creciente despersonalización burocrática del capitalismo multinacional y por la crisis del petróleo (1973) que introduce la experiencia de la inflación en la clase media estadounidense.

De modo que la persistencia en recomponer los colapsos financieros (como sucede, también, con esa reactivación constante de la Gran 
Depresión) demuestra que el estereotipo de la familia es un «objeto de una nostalgia utópica» porque, en la memoria popular, se halla entrelazado a un contexto id́lico de prosperidad, crecimiento y estabilidad económica. Y no puedo más que interrogarme si acaso esta recurrencia no está delatando que los grandes temores colectivos nacen del mismo entramado capitalista, cuestión que, en términos de Jameson, llevaría a considerar nuevamente esa otra variable explicativa en torno a las intensidades como fenómeno posmoderno: ello es, como síntomas de un sujeto burgués en deterioro, desorientando ante el avance de los entramados multinacionales, que arrostra el «declinar de la competición capitalista que, en sus comienzos, dio origen a un ego adquisitivo y agresivo y a una identidad poderosa y edípica» $(2012$, p. 41$)$.

La caída del sujeto burgués y la ruptura de legitimidad gubernamental comulgan en un giro cultural, marcado por la pérdida del respeto por la ley y el orden, la desintegración de los valores del patriotismo y lo que delata, básicamente, una crisis de la autoridad que se alegoriza en las narraciones masivas mediante el deterioro de la figura paterna. Y si bien algo de ello introduce la premiada Breaking Bad (con su relato de ese padre de familia que comienza a traficar metanfetaminas para sostener a su familia), advierto que las series más actuales parecen haberlo extremado al hacer del quiebre de la vida suburbial su motivo privilegiado.

Pienso en ficciones como The Kominsky Method (Netflix, 2018) y Kidding (Showtime, 2018), las cuales muestran el esfuerzo de dos hombres por sostener un «estilo de vida americano», aunque no sepan bien cómo, pues han perdido su entorno familiar en ese intento de prosperar económicamente que estimula el imaginario del Self-made Man. En los albores de la tercera edad, ambos protagonistas deben no solo enfrentarse al acoso de los fantasmas del pasado, sino además conciliar con un hogar que no es tal, en tanto la persecución del éxito y la riqueza los dejó en el abandono. También, las lecturas de la contracara femenina no permanecen exentas a estos temores domésticos: tal es el caso de Mosaic (2018) y What/If (Netflix, 2019), relatos que retratan el esfuerzo desesperado de mujeres ricas y poderosas por frenar el paso de los años y la soledad, pero también el pavor ante el escarnio público por relacionarse con hombres más jóvenes, en lo que da cuenta, como bien pensara Roland Barthes, que tanto el miedo como el goce se vuelven inconfesables en nuestra cultura. 
Esta última parcela heterogénea de series, con algunas inflexiones del costumbrismo y cierto cuestionamiento del realismo narrativo, aparecen como soluciones imaginarias a las contradicciones sociales actuales de los Estados Unidos, como un intento por exponer la necesidad imperante de crecimiento y estabilidad económica, aunque ello ponga en riesgo la supervivencia de toda relación social. Observo, en estas narrativas, la pregunta insistente en torno a qué hacer una vez que el Sueño Americano ha sido alcanzado, como si el costo inmediato de su concreción sea, casualmente, un miedo sostenido a perderlo. En todos los casos, se trata de historias que trasladan la incertidumbre y el extrañamiento de este afecto a la misma intimidad del hogar, cartografiando allí, en palabras de Jameson, «un mundo material [que] aparece ante EL sujeto con intensidad acentuada, portando una misteriosa carga de afecto, descrita en los términos de la ansiedad y la pérdida de la realidad» (2008, p. 68).

\section{Conclusión}

Finalizo aquí, recordando una vez más lo que era el objetivo de mi reflexión: recuperar algunas hipótesis de la teoría afectiva de Fredric Jameson, pertinentes para interrogar el miedo como parte de un entramado narrativo donde lo que se exhibe son afectividades de distinto tipo. En tal sentido, este recorrido pretendió relevar solo algunas claves para el estudio del miedo en términos de una intensidad, detectando aquellos procedimientos de representación recurrentes que permiten dar cuenta de sus huellas en la materialidad artística.

El modo en que las experiencias episódicas de los personajes seriales deslizan escalas y cromatismos afectivos, la profusión de los espacios de lo íntimo y lo doméstico como enclaves predominantes para las desmesuras afectivas, y el efecto de extrañamiento como una matriz que atraviesa una heterogeneidad de géneros que hacen de lo insólito su lugar común, introducen elementos pertinentes para diseñar una regularización coherente de series actuales que escenifican los desbordes del miedo en el cuerpo social, al tiempo que expone nuevas posibilidades escénicas ante esa incapacidad del lenguaje para nominar ciertos estados existenciales de los sujetos. Se trata, empero, de procedimientos que vienen perfeccionándose desde los avatares de la Guerra Fría, allí cuando el Bien y Mal respondía a categorías identificables, pero que, al decir de 
Jameson, se verán reemplazados por esa «sospecha persistente» (2007[1992], p. 167).

Me inclino a pensar, por ello, que aquello que las ficciones seriadas están expresando no responde tanto a innovaciones en términos de fórmula narrativa (el debilitamiento de la estructura melodramática y, con ello, un desvanecimiento sistemático de la figura del Mal) o a secuelas inmediatas del 11-S, sino que, más bien, son el corolario de una larga tradición política del miedo y una historia de experimentación artística por resolverla. Pues, no puede eludirse que estos artefactos estéticos no hacen más que responder a las contradicciones históricas y los múltiples cambios introducidos por la posmodernidad, esa pauta cultural que es la expresión interna y superestructural de la dominación estadounidense. De allí que Jameson convoque a pensar las intensidades «menos como modalidades específicamente estéticas que como intensités locales, accidentes en el continuum de la vida contemporánea, rupturas y brechas en el sistema perceptivo del capitalismo tardío» (1990, p. 151). Se trata de una afirmación que, en futuras investigaciones, deberá impulsarnos a rastrear cómo el modelo de serie estadounidense y su modo de retratar las intensidades están imponiendo una Cultura del Miedo, un «American Way of Fear» que circula global y masivamente ante las lógicas de mercado.

\section{Referencias bibliográficas}

Arán, P. (2015), Pasiones y discursos. V Encuentro Internacional Giros Teóricos, los «puntos ciegos» de la teoría. Inédito.

Arán, P. (2019), Gótico. En García, F. (ed.). Dicionário Digital do Insólito Ficcional. En prensa.

Arfuch, L. (2018), La vida narrada. Memoria, subjetividad y politica. Villa María, Argentina: EDUVIM.

Augé, M. (2014), Los muevos miedos. Buenos Aires, Argentina: Paidós.

Baudrillard, J. (1993). Cultura y simulacro. Barcelona, España: Kairós.

Cascajosa Virino, C. (2016), La nueva edad dorada de la televisión norteamericana. Secuencias, (39), 7-31.

De Felipe, F. y Gómez, I. (2011), Ficciones colaterales: las huellas del 11-S en las series «made in USA». Barcelona, España: UOC. 
Gómez Ponce, A. (2018). Vistas del pasado. Las series televisivas después del 11-S. Animus. Revista Interamericana de Comunicação $\mathrm{Me}$ diática, 17 (34), 247-265.

Jameson, F. (1989). Documentos de cultura, documentos de barbarie. La narrativa como acto socialmente simbólico. Madrid, España: Visor.

Jameson, F. (1996). Teoría de la posmodernidad. Barcelona, España: Trotta.

Jameson, F. (2002). Dialectics of Disaster. South Atlantic Quarterly, 101 (2), 297-304.

Jameson, F. (2007[1992]). Signaturas de lo visible. Buenos Aires, Argentina: Prometeo.

Jameson, F. (2008). Posmodernismo. La lógica cultural del capitalismo avanzado. Vol. 1. Buenos Aires, Argentina: La Marca.

Jameson, F. (2012). El posmodernismo revisado. Madrid, España: Abada.

Jameson, F. (2013). Las antinomias del realismo. Barcelona, España: Akal.

Jameson, F. (2014). Las ideologías de la teoría. Buenos Aires, Argentina: Eterna Decadencia.

Jameson, F. (2018[1991]). La geopolitica estética. Cine y espacio en el sistema mundial. Buenos Aires, Argentina: Cuenco de Plata.

Lozano, J. (2004). 11-S todavía: semiótica del acontecimiento y la explosión. Cuadernos de Información y Comunicación, (9), 129-136.

Moïsi, D. (2017). Geopolitica de las series o el triunfo global del miedo. Barcelona, España: Errata Naturae.

Mondzain, M. J. (2016). ¿Pueden matar las imágenes? El imperio de lo visible y la educación de la mirada después del 11-S. Buenos Aires, Argentina: Capital Intelectual.

Pérez Pereiro, M. (2012). Alegoría televisiva post 11-S. La imaginación terrorista en la ficción seriada norteamericana. En Gaytán, E., Gil, F. y Ulled, M. (Eds.). Los mensajeros del miedo. Las imágenes como testigos y agentes del terrorismo, pp. 239-258. Madrid, España: RIALP.

Piglia, R. (2001). Teoría del complot. Revista Plácidos Domingos, 4-15.

Robin, C. y Boucheron, P. (2016). El miedo. Historia y usos politicos de una emoción. Buenos Aires, Argentina: Capital Intelectual.

Žižek, S. (2006). On 9/11, New Yorkers faced the fire in the minds of men. The Guardian. Disponible en: https:/www.theguardian.com/ 
commentisfree/2006/sep/11/comment.september11 [Último acceso: $23 / 11 / 2018]$.

Žižek, S. (2013). Bienvenidos al desierto de lo real. Madrid, España: Akal. Žižek, S. (2019). Game of Thrones tapped into fears of revolution and political women - and left us no better off than before. The Independent. Disponible en:

https://www.independent.co.uk/voices/game-thrones-season-8-finale-bran-daenerys-cersei-jon-snow-zizek-revolutiona8923371.html [Último acceso: 22/05/2019]. 